\title{
UMA PROPOSTA DIDÁTICA SOBRE O ENSINO DE ELETRICIDADE COM ABORDAGEM INVESTIGATIVA
}

\section{Proposal of a Physics Class with the Inquiry-based Learning}

\author{
Jeirla Alves Monteiro* \\ Afrânio de Araújo Coelho** \\ Gilvandenys Leite Sales ${ }^{* * *}$
}

\begin{abstract}
Resumo: O método investigativo tem como objetivo estimular os alunos a pensar, questionar e discutir assuntos abordados em sala de aula, através de situações problema ou enigmáticas. Visando oferecer alternativas para os profissionais do ensino de Física, o presente trabalho buscou sintetizar o ensino investigativo e apresentar uma proposta didática de eletricidade com uma abordagem investigativa, de modo que os professores de Física possam se basear e introduzir o método investigativo no cotidiano de aulas regulares de Física.
\end{abstract}

Palavras-chave: Ensino de Física. Método Investigativo. Eletricidade.

\begin{abstract}
From the second half of the nineteenth century, to the present day, science education has undergone changes. Many teaching methods were used during this period, one of these methods was inquiry-based learning (IBL). The Inquiry-based learning is a form of active learning that starts by posing questions, problems or scenarios. The present work seeks to synthesize IBL and present a proposal of a physics class, with the inquiry-based learning, so that physics teachers can base themselves and introduce the IBL in Physics class.
\end{abstract}

Keywords: Physics teaching. Inquiry-based learning. Electricity.

\section{Introdução}

Há tempo que se tem discutido e estudado por pesquisadores a necessidade da renovação e da reformulação no ensino de Física no Ensino Médio (ARAÚJO e ABIB, 2003). Essa necessidade se dá pelas dificuldades que os alunos do Ensino Médio apresentam na disciplina de Física, que é reiteradamente considerada difícil, inclusive até por professores:

Ensinar física é difícil. O ensino dessa matéria possui características muito peculiares, que abrangem diferentes áreas: a própria física, que engloba um amplo

\footnotetext{
* Aluna do programa de Mestrado Acadêmico em Ensino de Ciências e Matemática (PGECM) da instituição Instituto Federal do Ceará (IFCE).

** Doutor em Meteorologia pela Université de Toulouse III - Paul Sabatier (1996). Professor associado III do departamento de física da Universidade Federal do Ceará (UFC).

**** Doutor em Engenharia de Teleinformática pela Universidade Federal do Ceará (UFC). Professor titular do Instituto Federal do Ceará (IFCE), atuando no Ensino Técnico Integrado, nas Licenciaturas de Física e Matemática, no Mestrado em Ensino de Ciências e Matemática e no Mestrado em Ciências da Computação.
} 
conhecimento e envolve ideias cada vez mais abstratas sobre uma parte do mundo natural (ROBILLOTA e BABICHAK, 1997, p.35).

Segundo Bezerra et al. (2009), há uma pequena evolução no ensino-aprendizagem de Física, que busca uma aproximação com o dia a dia do aluno, tornando-o, assim, mais contextualizado no cotidiano do aluno. Como consequência disto, pode-se observar uma renovação nos livros didáticos, promovida essencialmente pelo Programa Nacional do Livro Didático para o Ensino Médio - PNLEM, que cada vez mais apresenta maneiras de aplicar os conhecimentos da Física no dia a dia do aluno.

Moreira (2000) afirma que, desde a metade do século XX, as atividades experimentais ligadas ao ensino de Física são essenciais para o processo de aprendizagem, mas ainda hoje essas atividades não são devidamente exploradas nas escolas, onde se prevalece o uso do livro didático. Um agravante neste sentido, segundo esse autor, é que a maioria das escolas públicas, não possuem uma infraestrutura suficiente para comportar um bom laboratório didático de Física, o que impossibilita a implementação de um curriculum mais experimental para a disciplina de Física. Com efeito, ao basear-se no levantamento do Censo 2011, Soares Neto et al. (2013) inferiu que apenas $0,6 \%$ das escolas no país apresentam uma infraestrutura em que consta um laboratório didático de Ciências.

O presente artigo buscou reunir as características do ensino por investigação, abordadas nas obras de diferentes autores, os aspectos históricos do método investigativo, além da aplicação prática dessa metodologia em sala de aula.

\section{Ensino por investigação}

No século XIX, percebe-se uma preocupação de alguns estudiosos do ensino de ciências em incentivar algumas atividades investigativas no ensino de ciências da natureza. A perspectiva de um ensino investigativo foi predominante na política educacional dos Estados Unidos, influenciada pelo pensamento do filósofo e pedagogo americano John Dewey (1859 - 1952) (ZÔMPERO e LABURÚ, 2011). Na metade do século XIX, alguns cientistas americanos e europeus começaram a reivindicar um ensino de Ciências mais elaborado (ZÔMPERO e LABURÚ, 2011). Até aquela época, segundo Deboer (2006), o ensino de Ciências possuía um currículo clássico que priorizava o estudo de matemática e de gramática. No entanto, começava a ganhar força as propostas de alguns pensadores, notadamente de cientistas, de que o ensino de Ciências deveria ser conciliado com pesquisas investigativas em laboratórios didáticos. Segundo esses pensadores, o ensino das Ciências naturais era essencial para a formação humana.

Nesse período, o ensino com base investigativa apresentou três fases: a descoberta, em que os alunos exploravam o mundo natural; a verificação, ao utilizarem o laboratório para confirmar princípios científicos; e a investigação, em que os alunos tinham que descobrir algo, e depois provar soluções para aquelas questões utilizando o método científico (DEBOER, 2006).

No início do século XX, com o crescimento da urbanização, o ensino científico teve como base os valores sociais. Nessa época, o ensino de Ciências era dividido entre atividades investigativas e aulas tradicionais (ZÔMPERO e LABURÚ, 2011). Na década de 50, os pesquisadores e líderes industriais começaram a dizer que o ensino de Ciências tinha perdido seu rigor acadêmico. 
Quando os soviéticos lançaram o satélite Sputnik, acendeu uma disputa entre o governo americano e o regime soviético; com isso, o ensino científico foi novamente direcionado ao rigor acadêmico, ou seja, as atividades investigativas foram suspensas (BARROW, 2006). Mas na década de 1970, com o aumento da poluição industrial, o ensino de Ciências voltou a ter uma abordagem investigativa e uma preocupação ambiental e social (ZÔMPERO e LABURÚ, 2011).

Na década de 1980, um documento chamado Science For All Americans foi elaborado pela American Association for The Advancement of Science - AAAS, nos Estados Unidos. Nesse documento foi destacada a importância do ensino investigativo nas disciplinas de Ciências da Natureza. Segundo Barrow (apud Zômpero e Laburú, 2011), os alunos, a partir dali, teriam que aprender determinados procedimentos, como: observar, anotar, manipular, descrever, fazer perguntas e tentar encontrar respostas para as perguntas.

No Brasil, o ensino investigativo pôde ser encontrado nos parâmetros curriculares nacionais a partir de 1997. Mas, segundo Sá et al. (2007), o ensino por investigação ainda não está bem estabelecido.

\section{Concepções para o ensino investigativo}

O ensino investigativo focado em demonstrações de experimentos, tal como proposto nesse trabalho, é um procedimento metodológico com grande relevância para o ensino de Ciências. Com efeito, para Delizoicov e Angotti (2000), tais atividades despertam a curiosidade dos alunos, favorecendo o envolvimento destes nas aulas de Ciências. Porém, há várias formas de realizar tal procedimento metodológico.

Considerando que a Ciência surgiu da dúvida, de problemas e de questionamentos, o ensino de Ciências baseado na investigação deve assemelhar-se ao fazer Ciência, ou seja, partir de questionamentos na sala de aula para poder iniciar o ciclo investigativo.

Campos (1999) aponta que o ciclo investigativo deve surgir de uma situação problema, aberta e confusa. A investigação começa pela análise qualitativa do tema estudado. Depois, parte-se para a elaboração de hipóteses ou modelos que podem ser testados experimentalmente ou a partir de conhecimentos já adquiridos. Ao final do ciclo, tem-se a interpretação dos resultados obtidos. Segundo o autor, a experimentação investigativa deve ser mediada pelo professor, que deve confrontar o aluno utilizando questionamentos, valorizando suas interlocuções:

\footnotetext{
Para isso, é importante que o professor estimule e valorize as indagações dos alunos. Suas primeiras tentativas de respostas merecem não só o respeito do professor, mas também ser consideradas verdadeiras hipóteses explicativas com as quais trabalhará (CAMPOS, 1999, p.145).
}

Campos (1999) salienta que o professor deve orientar as hipóteses dos alunos, para que esses não se desviem do foco, que é o problema ou questionamento inicial. Por conta disso, o professor deve exercer o papel de orientador, segundo as instruções abaixo:

a) Incentivar os alunos a formular hipóteses explicativas.

b) Auxiliar na elaboração das hipóteses e dos experimentos para testá-las.

c) Possibilitar a efetiva comprovação experimental das hipóteses dos alunos. 
d) Colaborar nas discussões, evitando que os alunos se desviem demais do objetivo central.

e) Propor atividades em que o aluno perceba claramente o que e por que vai fazer, e as relações com aquilo que já foi feito. (CAMPOS, 1999, p.150).

O método investigativo, muitas vezes, é associado exclusivamente às aulas de laboratório; esta é uma associação equivocada, pois o ensino por investigação pode facilmente ser posto em prática na sala de aula regular. O que muitas vezes impede que isso ocorra é a falta de informação que o professor tem sobre o método. Para Campos (1999), quando se tem interesse em fazer uma aula investigativa na sala de aula, basta o professor criar uma situação problema inicial que seja intrigante para os alunos, de modo a levá-los a debaterem entre si. Um exemplo de situação problema, que pode ser abordada em uma aula de óptica, é: “O que é luz?". Essa simples pergunta pode ocasionar uma série de debates na sala de aula. Sem que o professor ofereça respostas prontas aos questionamentos dos alunos, tal como ocorre no dito ensino tradicional, este deve confrontá-los à realidade dos fatos, a razão de conceitos, aos princípios e às leis já debatidas em sala de aula, a fim de dirigir os alunos a uma reflexão acerca de suas próprias concepções e interpretações do fenômeno em tela.

A utilização de demonstrações e de experiências ilustrativas na sala de aula, como os ditos experimentos de baixo custo, proposta desse trabalho, é inteiramente propícia ao ensino investigativo, pois pode servir como ponte entre a realidade e a teoria explicativa. Ainda, estas demonstrações podem possibilitar o contato com materiais, situações concretas ou fenômenos que os alunos teriam dificuldades em conceber de outra forma, especialmente por abstração (CAMPOS, 1999).

\section{Diferentes abordagens investigativas}

Existem várias formas de abordagens para utilização de práticas investigativas. $\mathrm{O}$ quadro abaixo (Quadro 1) enumera, resumidamente, várias abordagens na visão de diferentes autores.

Quadro 1 - Resumo analítico de propostas de ensino por investigação

\begin{tabular}{|c|c|c|c|c|c|}
\hline $\begin{array}{c}\text { Momentos do } \\
\text { Processo }\end{array}$ & $\begin{array}{c}\text { Del Carmen } \\
(1988)\end{array}$ & $\begin{array}{c}\text { Olivera } \\
(1992)\end{array}$ & $\begin{array}{c}\text { Zabala } \\
(1992)\end{array}$ & $\begin{array}{c}\text { Gil } \\
(1993)\end{array}$ & $\begin{array}{c}\text { Garcia } \\
(1993)\end{array}$ \\
\hline $\begin{array}{c}\text { Escolha do objeto } \\
\text { de estudo e do } \\
\text { problema }\end{array}$ & $\begin{array}{c}\text { Planejamento e } \\
\text { clarificação do } \\
\text { problema }\end{array}$ & $\begin{array}{c}\text { Escolha do } \\
\text { objeto de estudo }\end{array}$ & $\begin{array}{c}\text { Explicitação } \\
\text { de perguntas }\end{array}$ & $\begin{array}{c}\text { Situação } \\
\text { problemática }\end{array}$ & $\begin{array}{c}\text { Contato inicial, } \\
\text { formulação do } \\
\text { problema }\end{array}$ \\
\hline $\begin{array}{c}\text { Expressão } \\
\text { das ideias } \\
\text { dos alunos. }\end{array}$ & $\begin{array}{c}\text { Definição, } \\
\text { hipóteses de } \\
\text { trabalho } \\
\text { hipóteses }\end{array}$ & $\begin{array}{c}\text { Definição de } \\
\text { hipóteses }\end{array}$ & $\begin{array}{c}\text { Hipóteses, } \\
\text { respostas } \\
\text { intuitivas }\end{array}$ & $\begin{array}{c}\text { Construção } \\
\text { de modelos e } \\
\text { hipóteses }\end{array}$ & $\begin{array}{c}\text { Interação com } \\
\text { as informações } \\
\text { dos alunos }\end{array}$ \\
\hline $\begin{array}{c}\text { Planejamento } \\
\text { da }\end{array}$ & $\begin{array}{c}\text { Planejamento } \\
\text { da investigação } \\
\text { investigação }\end{array}$ & $\begin{array}{c}\text { Planejamento da } \\
\text { investigação }\end{array}$ & $\begin{array}{c}\text { Fontes de } \\
\text { informações, } \\
\text { tomada de } \\
\text { dados }\end{array}$ & & $\begin{array}{c}\text { Elaboração de } \\
\text { estratégias } \\
\text { para incorporar } \\
\text { novas }\end{array}$ \\
informações
\end{tabular}


Revista de Educação, Ciência e Tecnologia

\begin{tabular}{|c|c|c|c|c|c|}
\hline $\begin{array}{c}\text { Nova } \\
\text { informação }\end{array}$ & $\begin{array}{l}\text { Aplicação de } \\
\text { instrumentos } \\
\text { de } \\
\text { investigação }\end{array}$ & $\begin{array}{c}\text { Materiais e } \\
\text { instrumentos }\end{array}$ & $\begin{array}{l}\text { Tomada } \\
\text { de dados }\end{array}$ & $\begin{array}{l}\text { Realização } \\
\text { de atividades }\end{array}$ & $\begin{array}{l}\text { Interação da } \\
\text { informação } \\
\text { nova } \\
\text { e preexistente }\end{array}$ \\
\hline $\begin{array}{l}\text { Interpretação } \\
\text { dos } \\
\text { resultados } \\
\text { e conclusões }\end{array}$ & $\begin{array}{l}\text { Comunicação, } \\
\text { discussão, } \\
\text { valoração }\end{array}$ & $\begin{array}{c}\text { Comunicação } \\
\text { da } \\
\text { investigação. } \\
\text { Publicação de } \\
\text { trabalhos }\end{array}$ & $\begin{array}{c}\text { Seleção, } \\
\text { classificação } \\
\text { de dados e } \\
\text { conclusão }\end{array}$ & $\begin{array}{c}\text { Interpretação } \\
\text { dos resultados, } \\
\text { relação } \\
\text { hipóteses } \\
\text { e corpo teórico }\end{array}$ & \\
\hline $\begin{array}{c}\text { Expressão e } \\
\text { comunicação } \\
\text { dos } \\
\text { resultados }\end{array}$ & $\begin{array}{l}\text { Comunicação, } \\
\text { discussão, } \\
\text { valoração }\end{array}$ & $\begin{array}{c}\text { Comunicação } \\
\text { da } \\
\text { investigação. } \\
\text { Publicação de } \\
\text { trabalhos }\end{array}$ & $\begin{array}{l}\text { Expressão, } \\
\text { comunicação }\end{array}$ & $\begin{array}{l}\text { Comunicação, } \\
\text { intercâmbio } \\
\text { entre equipes }\end{array}$ & $\begin{array}{c}\text { Elaboração } \\
\text { da informação } \\
\text { existente, } \\
\text { recapitulação }\end{array}$ \\
\hline $\begin{array}{l}\text { Recapitulação } \\
\text { e síntese }\end{array}$ & $\begin{array}{c}\text { Sínteses. } \\
\text { Identificação. } \\
\text { Modelos } \\
\text { explicativos }\end{array}$ & & & $\begin{array}{c}\text { Sínteses, } \\
\text { esquemas, } \\
\text { mapas } \\
\text { conceituais }\end{array}$ & \\
\hline $\begin{array}{l}\text { Aplicação a novas } \\
\text { situações }\end{array}$ & & & Generalização & $\begin{array}{l}\text { Possibilidades } \\
\text { de aplicação }\end{array}$ & $\begin{array}{c}\text { Aplicação, } \\
\text { generalização }\end{array}$ \\
\hline Metacognição & & & & & $\begin{array}{c}\text { Reflexão sobre } \\
\text { o processo }\end{array}$ \\
\hline Atuação no meio & & $\begin{array}{l}\text { Proposta de } \\
\text { intervenção, } \\
\text { ações }\end{array}$ & & & \\
\hline
\end{tabular}

Fonte: Rodriguez et al, 1995. p: 12.

Ao analisar o quadro acima, percebe-se que, mesmo com as diferenças nas formas de trabalho de cada autor, todos compartilham da mesma concepção, ou seja, em uma aula investigativa, é necessária uma questão problema para iniciar o trabalho com a turma. Segundo Rodriguez (1995), essa questão problema pode ser tomada por iniciativa do aluno ou do professor, mas é indispensável que os alunos se interessem por esse problema que vai ser investigado, de modo que fiquem instigados a resolvê-lo.

De acordo com o Quadro 1, percebe-se que há muitas formas de se pôr em prática o método investigativo. Cabe ao professor analisar a turma que será trabalhada, quanto às suas potencialidades e limitações, de modo que ele possa encontrar a forma ideal para introduzir a abordagem investigativa na sala de aula. Descreve-se abaixo três atividades que podem ser trabalhadas em sala de aula, de acordo com a classificação de Azevedo (2006).

\subsection{Demonstrações investigativas}

De acordo com Azevedo (2006), demonstrações investigativas são demonstrações experimentais que envolvem uma investigação acerca dos fenômenos naturais que pode, por exemplo, envolver demonstrações com materiais de baixo custo. Essas partem de um problema centrado sobre a demonstração de um determinado princípio ou fenômeno que será estudado e 
que levam à investigação (AZEVEDO, 2006). O presente trabalho, utiliza-se desse tipo de atividade.

Dentre as muitas contribuições que atividades experimentais investigativas trazem ao ensino de Física, Azevedo (2006) lista algumas:
a) Percepção de concepções espontâneas por meio da participação do aluno nas diversas etapas da resolução de problemas.
b) Valorização de um ensino por investigação.
c) Aproximação de uma atividade de investigação científica.
d) Maior participação e interação do aluno em sala de aula.
e) Valorização da interação do aluno como objeto de estudo.
f) Valorização da aprendizagem de atitudes e não apenas de conteúdo.
g) Possibilidade da criação de conflitos cognitivos em sala de aula. (AZEVEDO, 2006, p.27).

\subsection{Laboratório aberto}

Conforme Azevedo (2006), o Laboratório Aberto é como qualquer outra atividade investigativa, começa com uma questão problema que deverá ser respondida; mas, neste caso, por meio de uma experiência que deve ser executada em laboratório didático adequado. A autora dividiu o processo de resolução do problema em seis etapas: 1. Proposta do problema; 2. Levantamento de hipóteses; 3. Elaboração do plano de trabalho; 4. Montagem do arranjo experimental e coleta de dados; 6 . Análise de dados; 7. Conclusão.

Ressalta-se, por um lado, que a proposta de Azevedo (2006) para esse tipo de aula investigativa não se apropria de uma sequência específica como aquelas indicadas na Tabela 1 , mas representa uma amálgama daquelas diretivas. Por outro lado, não propõe etapas de comunicação, explicação, publicação e generalização.

\subsection{Problemas abertos}

De acordo com Azevedo (2006), Problemas Abertos são situações gerais apresentadas na sala de aula, onde são discutidos desde as condições de contorno até as possíveis soluções para a situação problematizada. A resolução de problemas abertos pode ser bastante demorada, pois ele abrange diversos aspectos, e se for do interesse do aluno, pode até se relacionar com a tríade Ciência, Tecnologia e Sociedade. Diferentemente de problemas com enunciados fechados, que limitam, senão impedem a formulação de hipóteses, problemas com enunciados abertos instigam o lançamento de hipóteses e a articulação de grandezas físicas que intervêm no problema (Gil et al., 1992). Sem dados definidos, os alunos são obrigados a desenvolver sua criatividade e a estruturar cientificamente seus pensamentos.

\section{Proposta de aula investigativa}

Um minucioso plano de aula com abordagem investigativa foi elaborado como parte de um trabalho de conclusão de curso da Licenciatura em Física da Universidade Federal do Ceará (MONTEIRO, 2016). O plano de aula, com duração de 50 (cinquenta) minutos, envolve os seguintes conteúdos de Eletricidade: fontes de voltagem; geradores e resistência elétrica. Pretende-se que o aluno, após a aula, possa compreender o funcionamento de uma lâmpada incandescente por meio de uma demonstração investigativa (Azevedo, 2006), possibilitando que este ponha em prática a habilidade de argumentação, que construa conceitos científicos a partir 
de uma questão problema relacionada a um experimento simples feito em sala de aula. As etapas da abordagem investigativa seguem, em parte, a sequência didática sugerida por Gil Perez e Castro (1996), quais sejam: (i) escolha do objeto de estudo e do problema; (ii) construção de modelos e hipóteses; (iii) realização de atividades; (iv) interpretação dos resultados; (v) recapitulação e síntese.

Figura 1 - Mina de grafite aquecida por efeito Joule ao ser presa a terminais elétricos e coberta por um frasco de vidro, a simular uma lâmpada incandescente

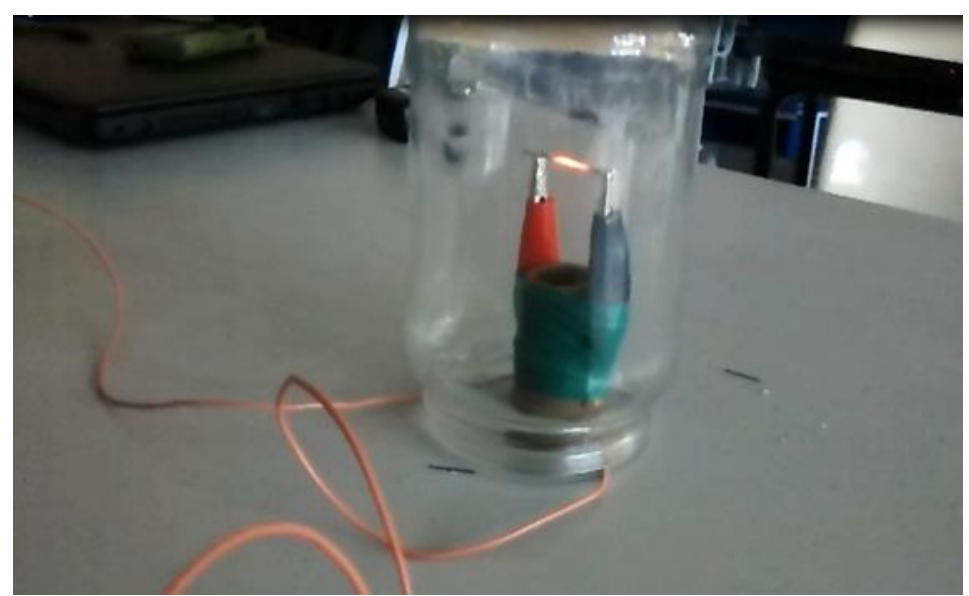

Fonte: Elaboração dos autores

A demonstração consiste em um circuito elétrico simples cuja fonte são baterias de tipo $\mathrm{D}$ associadas em série e a resistência elétrica é uma mina de grafite número 0.5 (Figura 1). Desta forma, o circuito, ao ser fechado, provoca o aquecimento da mina de grafite por efeito Joule que, a alta temperatura, irradia luz visível tal como o filamento de uma lâmpada incandescente. Ao cabo de pouco mais de um minuto, o grafite queima-se e emite luz intensa (Figura 2), o que pode provocar grande atenção e admiração dos alunos. Trata-se de uma demonstração feita com material e de montagem simples e que pode ser visualizado facilmente em vídeos na Internet.

Figura 2 - Mina de grafite ao queimar-se no circuito elétrico e emitir forte luz.

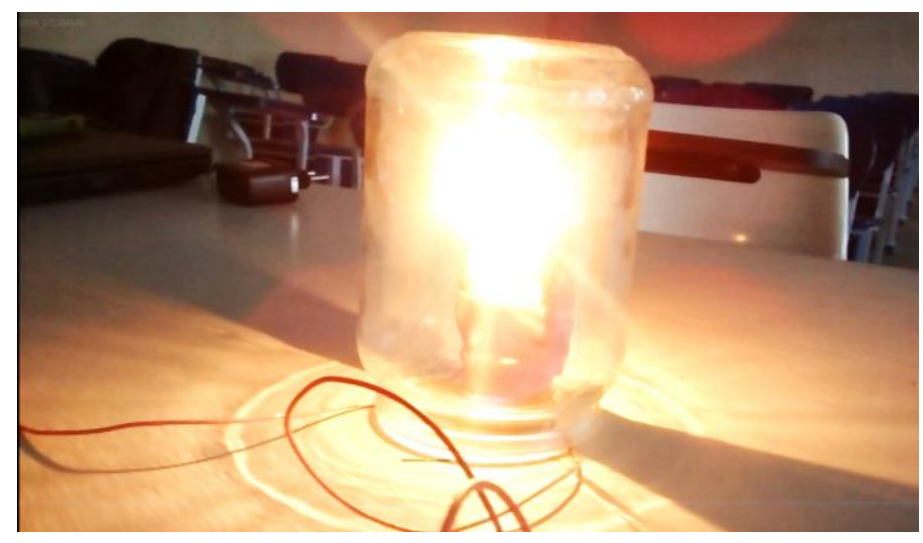

Fonte: Elaboração dos autores

Por tratar-se de uma aula com abordagem investigativa, esta inicia-se e desenvolvese através de perguntas aos alunos acerca da demonstração, acima descrita, e discussões em torno das respostas e questionamentos dos alunos. O professor deve conduzir a turma à 
construção do significado do conceito de resistência elétrica por meio de uma discussão socrática. Nesse sentido, o professor pode refazer novas demonstrações que reforcem ou refutem os argumentos dos alunos.

Ao iniciar a aula, o professor lança algumas perguntas aos alunos, como, por exemplo: "Vocês sabem como funciona uma lâmpada incandescente?". Após ouvir as respostas dos alunos e sem fornecer respostas, o professor apresenta a demonstração acima descrita para a turma.

A demonstração deve durar cerca de um minuto e meio. Após o término da ilustração, o professor deve colocar questões problema mais específicas, relacionadas à demonstração, como por exemplo: "Por que o grafite emite luz? Quais são os fatores para que isso ocorra?" Várias respostas distintas poderão ser dadas pelos alunos para as perguntas. O professor deve ouvir atentamente os alunos sem descartar nenhuma resposta ou colocação. Nesse momento, sugerimos que o professor não expresse como erradas determinadas respostas e afirmações equivocadas dos alunos. Com efeito, o professor deve buscar compreender as ideias e significados subjacentes a essas concepções consideradas espontâneas ou alternativas.

O professor deve confrontar essas concepções dos alunos fazendo-lhes novas perguntas ou afirmações que conduzam à discussão em torno do tema central da aula para a construção de conceitos específicos. Neste sentido, o professor deve utilizar o método investigativo ao seu favor, induzindo os alunos a refletir sobre a coerência e a justeza de seus argumentos.

Ao considerar como hipóteses determinadas respostas dos alunos, no intuito de testálas, o professor pode realizar modificações no experimento base. Essas modificações devem girar em torno do comprimento dos fios, da quantidade de pilhas em série, da espessura do grafite, dentre outras possibilidades, a depender das hipóteses e das indagações lançadas pelos alunos que podem ser testadas e respondidas com novas demonstrações. Perguntas possíveis podem ser do tipo: "Seria possível acender outro material, por exemplo, um Led? E se o grafite fosse mais grosso, ele ainda acenderia? A quantidade de pilhas influencia? O tamanho dos fios influencia?".

O professor finaliza a aula com um resumo teórico explicativo da demonstração. Nesse momento, valida-se determinadas hipóteses e associa-se certas concepções dos alunos com conceitos formais da Física, necessários para a devida interpretação teórica da demonstração.

\section{Aplicação}

As aulas foram realizadas em uma escola pública estadual situada no município de Fortaleza, Ceará, com uma turma do terceiro ano do Ensino Médio. À época dessa intervenção, o laboratório didático de Física tinha baixa frequência de utilização.

No dia da intervenção, havia na turma 23 (vinte e três) alunos, fato que facilitou bastante durante o período de organização preliminar da aula, que consistiu em organizar a sala de aula de uma forma que todos pudessem visualizar a execução do experimento (acredita-se que um número maior de alunos poderia atrapalhar). 
O assunto proposto no plano de aula foi escolhido com o aval do professor regular daquela turma e inseriu-se no conteúdo já programado para aquele período escolar. A escolha do experimento ilustrativo que deveria fazer parte do plano de aula teria de abordar os seguintes temas: (I) resistência e corrente elétrica; (II) fontes de voltagens. Por esta razão, escolheu-se a ilustração supracitada, a lâmpada incandescente.

Primeiramente, ao iniciar-se a aula na turma, os alunos foram informados que aquela aula seria atípica, que necessitava o máximo da atenção deles. Esse apelo, por si só, já atraiu a curiosidade dos alunos. Depois, foi solicitado para que os alunos aproximassem suas carteiras da mesa do professor. Depois que os alunos organizaram suas carteiras como solicitado, pediuse novamente que eles ficassem bem atentos, para que pudessem observar o experimento em funcionamento.

Antes de começar o experimento, questionou-se se os alunos sabiam como funcionava uma lâmpada incandescente. Foram muitas as respostas, mas nenhuma conceitualmente correta. Então, foi avisado naquele momento que eles deveriam observar uma lâmpada incandescente feita com mina de grafite. Alguns alunos duvidaram e disseram que não seria possível. Então, iniciou-se o experimento e foi pedido, mais uma vez, para que eles observassem atentamente.

Ao término da apresentação do experimento, as discussões sobre o experimento começaram por uma pergunta principal, qual seja: "Por que o grafite emitiu luz?". Os alunos deram várias respostas e fizeram várias perguntas. Algumas dessas perguntas e respostas estão descritas no Quadro 2. emite luz?"

Quadro 2 - Algumas respostas e perguntas dos alunos referente ao questionamento "Por que o grafite

\begin{tabular}{|c|c|}
\hline Respostas dos alunos & Perguntas dos alunos \\
\hline "Por causa das pilhas" & "Esse grafite é um grafite comum?" \\
\hline "Porque tem um grafite especial" & "As pilhas são diferentes das normais?" \\
\hline "Porque tem um gás, dentro do copo" & "Se colocar menos pilhas, ainda vai funcionar?" \\
\hline "Por causa da eletricidade" & "Se tirar o copo de cima, ainda vai acender?" \\
\hline
\end{tabular}

Fonte: Elaboração dos autores

Tal como preconizado pela proposta do método investigativo, o professor não deve responder diretamente as perguntas dos alunos; buscou-se, por outro lado, confrontar as perguntas a partir de modificações no experimento base. Esperou-se, portanto, que novas demonstrações modificadas pudessem, por si só, responder as indagações e ainda contradizer, ou confirmar, certas afirmações. As modificações que foram feitas no experimento estão descritas no Quadro 3.

Quadro 3 - Modificações que foram feitas no experimento com base nas indagações dos alunos e resultados obtidos.

\begin{tabular}{|c|c|}
\hline Modificações no experimento & Resultado do experimento \\
\hline O número de pilhas foi reduzido de oito para sete & Não houve emissão de luz \\
\hline A mina de grafite $0.5 \mathrm{~mm}$ foi trocada por uma mina $0.7 \mathrm{~mm}$ & Não houve emissão de luz \\
\hline O copo de vidro de proteção foi removido & Houve emissão de luz \\
\hline O tamanho dos fios foi reduzido de $20 \mathrm{~cm}$ para $12 \mathrm{~cm}$ & Houve emissão de luz \\
\hline As presas no formato jacaré foram retiradas dos fios & Houve emissão de luz \\
\hline
\end{tabular}

Fonte: Elaboração dos autores 
Toda vez que alguma modificação era feita, o experimento era reexecutado. Ao depender dessa modificação, a mina de grafite emitia ou não luz. Por exemplo, quando o copo de vidro foi removido e quando o tamanho dos fios foi reduzido, a mina de grafite queimou emitindo luz normalmente. Porém, quando o número de pilhas foi diminuído e quando a mina de grafite de $0.5 \mathrm{~mm}$ foi trocada por uma de $0.7 \mathrm{~mm}$, o grafite não emitiu luz.

Ao término da aula, um aluno foi escolhido para que fizesse uma síntese daquela aula para o restante da turma, especialmente daquilo que ele havia compreendido sobre o assunto em tela. Esse aluno saiu-se bem, pois ele descreveu corretamente as situações físicas que ocorreram no experimento. Esta teve uma duração de 50 minutos.

\section{Resultados e discussões}

Sem a pretensão de delinear um formato de pesquisa mais formal a esse trabalho, buscouse na atividade de campo descrita acima, responder aos seguintes questionamentos: "Os alunos se interessam por aulas de física em que ocorram experimentos ilustrativos? Os alunos se interessam em fazer questionamentos acerca do experimento?”.

Segundo Campos (1999), para se iniciar um ciclo investigativo, os alunos precisam ser estimulados com situações intrigantes. Na intervenção descrita acima, a pergunta inicial foi: "Por que o grafite emite luz?". Essa pergunta abriu as portas para várias discussões e questionamentos, e isso fez toda a diferença ao comparar-se com aulas tradicionais. Pelo fato de os alunos terem sido confrontados pela pergunta inicial, eles ficaram mais atentos e consequentemente, participaram mais motivados da aula. Com essa intervenção em sala de aula, pôde-se observar que o ensino por investigação é realmente eficaz no quesito instigar a curiosidade dos alunos.

Almeida Júnior (1979) descreve vários obstáculos que a educação científica enfrenta nas escolas. Com efeito, durante a intervenção da aula investigativa, notou-se que a infraestrutura do colégio não estava adequada à sua realização como, por exemplo, a péssima qualidade acústica da sala de aula, que dificultou a compreensão dos questionamentos dos alunos por parte do professor, outro obstáculo epistemológico observado foi a apatia de alguns alunos, pois para a metodologia investigativa ser mais eficaz se faz necessário o engajamento de todos os alunos.

Blosser (1988) fala sobre objetivos pedagógicos que podem ser atingidos a longo prazo, com atividades de caráter investigativo. Esses objetivos são: desenvolver habilidades de questionar, investigar, comunicar e organizar ideias, entender conceitos e hipóteses, desenvolver habilidades cognitivas e ter uma maior compreensão sobre a natureza científica. Evidentemente, na turma em que houve a intervenção, não se pôde atingir todos esses objetivos, pois seriam necessárias mais aulas com esse tipo de abordagem, ou seja, o professor regular da turma teria que ministrar aulas e realizar atividades investigativas conjuntamente.

\section{Considerações finais}

De acordo com o que foi exposto, pôde-se sintetizar os aspectos de uma aula investigativa realizada por meio de uma atividade demonstrativa em quatro etapas. Na primeira etapa, para pôr em prática uma atividade experimental demonstrativa investigativa, tem-se que 
primeiro iniciar o ciclo investigativo, fazendo alguma pergunta que seja intrigante ou enigmática.

Na segunda etapa, deve-se ouvir com atenção as respostas e os questionamentos dos alunos. Porém, nessa etapa, considerando que muitos alunos podem lançar questionamentos e dar respostas em uma determinada turma, algumas bem diferentes umas das outras, não se pode levar em consideração todas elas, por questões de organização da aula. Desta forma, tem-se que escolher aquelas perguntas que podem ser respondidas por meio de uma nova demonstração, ou seja, que possa ser reproduzível pelo experimento em tela. Trata-se de uma etapa delicada, pois o professor deve ter o cuidado em não desmerecer aquelas perguntas julgadas irrelevantes.

$\mathrm{Na}$ terceira etapa, o professor deve responder as perguntas escolhidas, fazendo modificações no experimento base. É importante que essas modificações sejam previstas com antecedência. Na quarta e última etapa, a aula deve ser finalizada fazendo uma síntese de tudo o que foi discutido sobre o experimento; essa síntese pode ser feita pelo professor ou por um aluno. Prefere-se que seja feita por um aluno para que, por meio dele, a turma se sinta protagonista da construção de seu conhecimento, objetivo principal da proposta de aula desse trabalho.

O ensino por investigação é uma metodologia de ensino que induz os alunos a serem mais curiosos. Ela é utilizada principalmente em aulas que envolvam conteúdos conceituais, por isso se torna uma metodologia aberta para ser utilizada em qualquer disciplina. Espera-se que o presente trabalho possa incentivar os educadores, principalmente da área de Física, a utilizarem o método investigativo em suas aulas.

\section{Referências}

ALMEIDA JÚNIOR, J. B. de. A evolução do Ensino de Física no Brasil. Revista Brasileira de Ensino de Física, São Paulo, v.1, n. 2, p. 45-58, 1979.

ARAÚJO, M. S. T. e ABIB, M. L. V. dos S. Atividades Experimentais no Ensino de Física: Diferentes Enfoques, Diferentes Finalidades. Revista Brasileira de Ensino de Física, v. 25, n. 2, jun. 2003.

AZEVEDO, M.C.P.S. Ensino por investigação: problematizando as atividades em sala de aula. In: CARVALHO, Anna Maria Pessoa de. (Org). Ensino de ciências: unindo a pesquisa e a prática. São Paulo. Thomson, 2006.

BARROW, L. H. A Brief History of Inquiry: From Dewey to Standards. Journal of Science Teacher Education, 2006, n.17, p.265-278, Springer 2006.

BEZERRA, D. P; GOMES, E. C. S; MELO, E. S. N e SOUZA, T. C. A evolução do Ensino de Física: Perspectiva Docente. Revista Scientia Plena, v. 5, n. 9, set. 2009.

BLOSSER, P.E. O papel do laboratório no ensino de ciências. Tradução M.A Moreira. Cad. Cat. Ensino de Física, v.5, n.2, p. 74-78, 1988. 
CAMPOS, M. M. A Formação de professores para crianças de 0 a 10 anos: modelos em debate. Educação \& Sociedade, v.20, n.68, p.126-142, dez. 1999. (Número especial: Formação de profissionais da educação: políticas e tendências.)

DEBOER, G. E. Historical perspectives on inquiry teaching in schools. In: FLICK; LEDREMAN. Scientific inquiry and nature of science. Implications for teaching, learning, and teacher education. Springer, 2006.

DELIZOICOV, D.; ANGOTTI, J. A. Metodologia do Ensino de Ciências. São Paulo: Cortez, 2000.

GIL PEREZ, D. e CASTRO, P. V. La orientación de las prácticas de laboratorio como investigación: un ejemplo ilustrativo. Enseñanza de las Ciencias, Barcelona, v.14, n.2, 155- 163. 1996.

GIL-PEREZ, D.; MARTINEZ-TORREGROSA, J.; RAMIREZ, L.; DUMAS-CARRÉ, A., GOFARD, M. e CARVALHO, A.M.P. Questionando a didática de resolução de problemas: elaboração de um modelo alternativo. Caderno Catarinense de Ensino de Física,v. 9, n.1, p.7-19, 1992.

MONTEIRO, J. A. Plano de aula de Eletricidade com abordagem investigativa: um estudo de caso. 2016. 48 f. Monografia (Licenciatura em Física) Centro de Ciências, Universidade Federal do Ceará, Fortaleza, 2016.

MOREIRA, M. A. Ensino de Física no Brasil: Retrospectiva e Perspectivas. Revista Brasileira de Ensino de Física, v. 22, n. 1, p. 94-99, mar. 2000

ROBILlOTA, M. R.; BABICHAK, C. C. Definições e conceitos em física. Cadernos Cedes, ano XVIII, n. 41, 1997, p. 35-45.

RODRIGUEZ, J. J.G; LEON, P.C. ¿Cómo enseñar? Hacia una definición de las estrategias de enseñanza por investigación. Investigación en la escuela, n. 25, 1995.

SÁ, E. F. de, PAULA, H. de F, LIMA, M. E. C.; AGUIAR, O. G. As características das atividades investigativas segundo tutores e coordenadores de um curso de especialização em ensino de ciências. In: ENCONTRO NACIONAL DE PESQUISA EM ENSINO DE CIÊNCIAS, 6, 2007, Florianópolis, SC. Atas..., 2007.

SOARES NETO, J. J.; JESUS, G. R.; KARINO, C. A.; ANDRADE, D. F. Uma Escala para Medir a Infraestrutura Escolar. Estudos em Avaliação Educacional, v. 54, n. 24, p. 78-99, 2013.

ZÔMPERO A.F, LABURÚ C.E. Atividades investigativas no ensino de ciências: Aspectos históricos e diferentes abordagens. Rev. Ensaio, Belo Horizonte, v.13, n.3, p.67-80, set-dez 2011.

Recebido em agosto de 2019.

Aprovado em outubro de 2019. 